\title{
p53 and ANXA4/NF-kB p50 complexes regulate cell proliferation, apoptosis and tumor progression in ovarian clear cell carcinoma
}

\author{
JUANJUAN LIU ${ }^{1 *}$, HUIMIN WANG ${ }^{1,2 *}$, MINGJUN ZHENG ${ }^{1}$, LU DENG $^{1}$, XUE ZHANG $^{1}$ and BEI LIN ${ }^{1}$ \\ ${ }^{1}$ Department of Obstetrics and Gynecology, Shengjing Hospital of China Medical University, Shenyang, Liaoning 110004; \\ ${ }^{2}$ Department of Gynecology, Liaoning Cancer Hospital, Shenyang, Liaoning 110000, P.R. China
}

Received February 1, 2020; Accepted July 22, 2020

DOI: $10.3892 / \mathrm{ijmm} .2020 .4757$

\begin{abstract}
Annexin IV (ANXA4) is highly expressed in ovarian clear cell carcinoma (OCCC); however, its underlying molecular mechanism in OCCC remains unknown. The present study aimed to identify the molecule that ANXA4 may act on and to determine its underlying molecular mechanism. Immunohistochemistry, co-immunoprecipitation and western blotting were performed to detect the expression and interaction of ANXA4, and its associated proteins. Furthermore, MTT assay, flow cytometry, western blotting and gene expression profile enrichment analysis were performed to identify the potential role and molecular mechanism of ANXA4 in OCCC. The results demonstrated that ANXA4 and nuclear factor- $\kappa$-light-chain-enhancer of activated B cells (NF- $\kappa$ B) p50 nuclear expression levels were significantly higher in OCCC tissues compared with other subtypes of ovarian cancer, such as serous and mucinous. In addition, a significantly positive correlation was observed between ANXA4 and NF- $\mathrm{BB}$ p50 expression in OCCC; however, the expression levels of mutant p53 and ANXA4 were negatively correlated in a linear manner. These results suggest that ANXA4 and NF- $\mathrm{B}$ p50 may be potential independent risk factors for poor prognosis. ANXA4 and NF- $\mathrm{B}$ p50 were demonstrated to interact and their expression was co-localized. The cBioPortal database was used to construct a protein-protein interaction network between ANXA4, NF- $\mathrm{AB}$ p50 and p53, and functional pathway analysis indicated that the genes were predominantly enriched in the cell cycle and during apoptosis. Transfection of the ANXA4 gene increased the expression of $N F-\kappa B$
\end{abstract}

Correspondence to: Professor Bei Lin, Department of Obstetrics and Gynecology, Shengjing Hospital of China Medical University, 36 Sanhao Street, Shenyang, Liaoning 110004, P.R. China

E-mail: linbei88@hotmail.com

*Contributed equally

Key words: ovarian clear cell carcinoma, Annexin IV, NF-кB p50, p53, cell cycle, apoptosis p50, as well as its downstream targets, Cyclin D1 and B-cell lymphoma-2 (Bcl-2). Furthermore, transfection of the ANXA4 gene increased proliferation and decreased apoptosis of OCCC

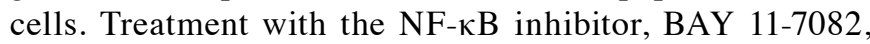
decreased Cyclin D1 and Bcl-2 expression levels. Collectively, the results of the present study suggest that wild p53 activates ANXA4 transcription, promotes its expression and enhances $\mathrm{NF}-\kappa \mathrm{B}$ p50 and ANXA4 interaction. This in turn activates the $\mathrm{NF}-\kappa \mathrm{B}$ signaling pathway, promotes cell cycle progression and inhibits apoptosis, thus contributing to the malignant progression of OCCC. Thus, ANXA4 and NF- $\mathrm{NB}$ p50 may be used as prognostic biomarkers, and may be molecular therapeutic targets in OCCC.

\section{Introduction}

Among tumors involving the female reproductive system, ovarian cancer (OC) currently has the highest mortality rate. According to statistics, there were 22,240 newly diagnosed ovarian cancer cases and 14,070 ovarian cancer mortalities in the United States in 2018 (1). Clear cell carcinoma is a subtype of OC, which accounts for $5-25 \%$ of all cases $(2,3)$. Previous studies have reported that ovarian clear cell carcinoma (OCCC) is relatively insensitive compared with conventional chemotherapeutics for $\mathrm{OC}$, including paclitaxel and platinum-based drugs, demonstrates a poor response to second-line chemotherapeutics, and there is also a lack of specific targeted chemotherapeutics for OCCC (4-6). Thus, the prognosis of OCCC is considered unfavorable compared with other subtypes of OC, such as serous and mucinous, whereby the 5-year survival rate is only $27 \%$ (7). Studying the occurrence and developmental mechanisms of OCCC has a significant value for targeted treatment and improving prognosis.

Annexin IV (ANXA4), a member of the annexin family, can reversibly bind with membrane phospholipids in a calcium ion-dependent form and participate in regulating the biological behavior of tumor cells, including proliferation, apoptosis, invasion and metastasis (8-10). A previous study demonstrated that ANXA4 expression is significantly upregulated in OCCC compared with ovarian serous carcinoma (11). Thus, it is speculated that ANXA4 is a specific marker of 
OCCC; however, the molecular mechanism by which ANXA4 regulates the biological behavior of OCCC remains unknown. In 2010, Jeon et al (12) reported that ANXA4 can enter the nucleus of the cervical cancer Hela cell line and influence the transcription of target genes associated with nuclear factor- $\kappa$-light-chain-enhancer of activated $\mathrm{B}$ cells $(\mathrm{NF}-\kappa \mathrm{B})$ $\mathrm{p} 50$. NF- $\mathrm{NB}$ is retained in the cytoplasm at a resting state by binding to inhibitor of $\kappa \mathrm{B}(\mathrm{I} \kappa \mathrm{B})$, the inhibitory protein of $N F-\kappa B$. When cells are stimulated by exogenous factors, such as inflammatory factors, oncogenes and viral infections, $\mathrm{I} \kappa \mathrm{B}$ is degraded via phosphorylation, thus releasing $\mathrm{NF}-\kappa \mathrm{B}$, which then enters the nucleus to function as a transcriptional factor, and induces the expression of target genes, including B-cell lymphoma-2 (Bcl-2) family, c-Jun N-terminal kinase, Cyclin D1, tumor necrosis factor and interleukin-1 (13-15). Consequently, the antiapoptotic activity of tumor cells is enhanced and tumor growth is promoted $(16,17)$.

This raises two questions, the first is whether ANXA4 interacts with $\mathrm{NF}-\kappa \mathrm{B}$ p50 in OCCC, and if so, how does this interaction influence the biological behavior of OCCC? Masuishi et al (18) reported that high ANXA4 expression in OCCC is regulated by wild-type p53. Wild-type p53, a key factor in regulating cell-cycle arrest, cell aging and apoptosis, is the most effective tumor-inhibiting gene, whereby exogenously-acquired wild-type p53 can inhibit autophagy, reverse drug resistance and promote apoptosis of tumor cells (19).

The present study aimed to investigate the expression levels of p53, ANXA4 and NF- $\mathrm{B}$ p50 in several subtypes of epithelial ovarian cancer tissues, and assess the association between their expression and OCCC clinicopathological characteristics, and prognosis. The structural association and interaction between ANXA4 and NF- $\kappa \mathrm{B}$ p50 were assessed via co-immunoprecipitation, confocal laser scanning microscopy and western blot analyses. In addition, a protein-protein interaction (PPI) network of ANXA4, NF- $\mathrm{BB}$ p50 and p53 proteins was constructed and enrichment analysis was performed to determine the underlying molecular mechanism of ANXA4 in OCCC. The results demonstrated that p53 and ANXA4/NF- $\kappa$ B p50 complexes activated the NF- $\kappa$ B signaling pathway, increased the expression levels of Cyclin D1 and $\mathrm{Bcl}-2$, promoted proliferation and inhibited apoptosis of OCCC cells.

\section{Materials and methods}

Ethical approval. The patient samples used in the present study were fully encoded to protect patient confidentially. All procedures involving human participants were approved by the Ethics Committee of Shengjing Hospital of China Medical University (Shenyang, China; approval no. 2013PS66K). The ethics committee waived the need for patient consent in this retrospective study, as the patient information was withheld.

Specimen samples. A total of 151 ovarian paraffin specimens with complete clinical and pathological data were collected from the Department of Gynecology at Shengjing Hospital of China Medical University between January 2003 and December 2012. For immunohistochemistry, resected ovarian tissues were immediately frozen in liquid nitrogen and stored at $-80^{\circ} \mathrm{C}$ until subsequent experimentation. Frozen sections $(5 \mu \mathrm{m})$ were cut on a cryostat, and control sections were stained with hematoxylin and eosin $(\mathrm{H} \& \mathrm{E})$ for $5 \mathrm{~min}$ at room temperature. Among these, 86 cases were OCCC, 30 cases were serous $\mathrm{OC}, 17$ cases were mucinous $\mathrm{OC}$, eight cases were intrauterine membrane-like $\mathrm{OC}$ and 10 cases were normal ovarian tissue (from ovariectomized patients with squamous cervical cancer during the same period). All tissue sections were blindly assessed by two pathologists from Shengjing Hospital of China Medical University (Shenyang, China) to obtain a definitive diagnosis.

The mean age of the OCCC group was 52.7 years (age range, 29-73 years), while the mean age of the other OC subtypes group and normal ovarian group was 50.2 years (age range, 16-77 years), and 49.4 years (age range, 46-57 years), respectively. No statistically significant differences were observed between the age of patients with OCCC, other subtypes of OC and normal ovarian tissues. Cancer staging was determined according to the 2014 International Federation of Gynecology and Obstetrics (FIGO) staging system (20). Among the 86 cases of OCCC, 51 were in stage I, eight were in stage II, 23 were in stage III and four cases were in stage IV. In addition, fours cases refused chemotherapy, 11 patients were lost to follow-up and the remaining 71 patients were given 6-8 cycles of paclitaxel plus platinum systemic chemotherapy following surgery, according to the National Comprehensive Cancer Network (NCCN) guidelines (21) and underwent regular follow-ups; there were 52 cases of sensitivity to chemotherapy and 19 cases of chemotherapy resistance. The outcomes for the 71 patients included 25 deceased patients, 1 patient who survived with recurrence and 45 patients who survived without tumors. None of the patients with ovarian cancer underwent chemotherapy prior to surgery. The NCCN criteria states that (1) the chemotherapy resistant group included patients who had a clinical response to the initial paclitaxel and carboplatin (TC) chemotherapy, but had cancer recurrence during the late stage of chemotherapy or within 6 months after completion of chemotherapy, (2) and the chemotherapy sensitive group included patients with clinical remission over 12 months after completion of chemotherapy with TC. Factors diagnostic for ovarian cancer relapse include: i) Continuously increased CA125 levels, ii) Solid lesions identified by gynecological examination, iii) Tumors identified by imaging, iv) Ascites and v) An intestinal obstruction of unknown etiology. Follow-up time was calculated from the date of surgery to the date of progression, death, and last visit or contact with the patient. Overall survival (OS) was defined as the time interval between the date of surgery and the date of death.

Immunohistochemistry (IHC). The ovarian tissue samples for immunohistochemical analyses were fixed in $4 \%$ paraformaldehyde for $48 \mathrm{~h}$ at room temperature and embedded in paraffin, according to conventional histological method (22). The paraffin-embedded tissue samples were cut into $5-\mu \mathrm{m}$ thick sections and the immunohistochemical expression of ANXA4, NF- $\kappa$ B p50 and wild-type p53 in tissue sections were determined using Strept Actividin-Biotin Complex (SABC) IHC staining (Boster Biological Technology). The tissue sections were deparaffinized in xylene at room temperature and rehydrated in a descending ethanol series $(100,100,95$, 90 and $75 \%$ ). Deparaffinized sections were incubated with 
$3 \% \mathrm{H}_{2} \mathrm{O}_{2}$ for $10 \mathrm{~min}$ at room temperature to inhibit endogenous peroxidase activity, blocked with $10 \%$ normal goat serum (cat. no. AR0009; Boster Biological Technology) for $30 \mathrm{~min}$ at $37^{\circ} \mathrm{C}$, and subsequently incubated with the following primary antibodies: Mouse anti-human ANXA4 (1:200; cat. no. sc-46693), mouse anti-human NF- $\mathrm{B}$ p50 (1:200; cat. no. sc-8414) and mouse anti-human wild-type p53 (1:50; cat. no. sc-126) for $2 \mathrm{~h}$ at $37^{\circ} \mathrm{C}$ (all purchased from Santa Cruz Biotechnology, Inc.). The slides were washed three times with phosphate buffered saline (PBS, Beyotime Institute of Biotechnology) and incubated with horseradish peroxidase-linked anti-mouse immunoglobulin $\mathrm{G}$ secondary antibody (1:2,000; cat. no. sc-2005; Santa Cruz Biotechnology, Inc.) for $1 \mathrm{~h}$ at room temperature. The slides were subsequently stained using the diaminobenzidine substrate kit (cat. no. SK-4100; Vector Laboratories, Inc.). The nuclei were stained with hematoxylin for $4 \mathrm{~min}$ at room temperature, and the slides were observed under an inverted light microscope (Olympus Corporation; magnifications x200 and $\mathrm{x} 400$ ). Tissue sections were blindly assessed by two pathologists from Shengjing Hospital of China Medical University (Shenyang, China). IHC results were interpreted, as previously described (22). Briefly, $0=$ no staining, $1=$ light yellow, $2=$ brownish yellow and $3=$ dark brown; positive cells were also counted under $\mathrm{x} 400$ magnification and scored $(0=$ positive rate $<5 \% ; 1=5-25 \% ; 2=26-50 \% ; 3=51-75 \%$ and $4=>75 \%$ ). The final staining score was determined by multiplying the two values: 0-2 was considered negative (-), 3-4 was (+), 5-8 was $(++)$, and 9-12 was $(+++)$. The symbols '-' and ' + ' represent low expression, and '++' and ' +++ ' represent high expression.

Cell culture and transfection. Human OCCC derived RMG-1 [donated by Professor Iwamori Masao of Tokyo University (Tokyo, Japan)] (23) and ES-2 (purchased from American Type Culture Collection) cell lines were cultured in RPMI-1640 medium or Macoy 5A supplemented with $10 \%$ fetal bovine serum (FBS), respectively, at $37^{\circ} \mathrm{C}$ in $5 \% \mathrm{CO}_{2}$ (all purchased from HyClone; GE Healthcare Life Sciences).

The human OCCC cells (ES-2 cells and RMG-1 cells) were plated into six-well plates at a density of $1.5 \times 10^{5}$ cells/well. After incubation at constant temperature $\left(37^{\circ} \mathrm{C}, 5 \% \mathrm{CO}_{2}\right)$, cells were transfected once they adhered to the plates. Cells were starved of serum for $1 \mathrm{~h}$ prior to transfection. The transfection mixture consisted of serum-free medium, $2.5 \mu \mathrm{g} / \mathrm{ml}$ ANXA4 overexpression vector (pc-ANXA4-GFP) or short hairpin (sh)-ANXA4-GFP or corresponding empty control vectors (all purchased from Shanghai GenePharma Co., Ltd.) and Lipofectamine 2000 (cat. no. L3000150; Invitrogen, Thermo Fisher Scientific, Inc.). The transfection procedure was performed base on the manufacturer's protocol of Lipofectamine 2000 transfection reagent. The following stable cell lines were generated: ES-2-A4-O, ES-2 cells transfected with pc-ANXA4-GFP plasmids and RMG-1-A4-I, RMG-1 cells transfected with Sh-ANXA4-GFP plasmids. Transfection efficiency was measured using western blot analysis. Subsequent experiments with transfected cells were performed following transfection for $24 \mathrm{~h}$.

Co-immunoprecipitation. ES-2 cells and RMG-1 cells were lysed using RIPA buffer (cat. no. sc-24948, Santa Cruz
Biotechnology, Inc.) (50 Mm Tris- $\mathrm{HCl}$ (pH 7.2), $150 \mathrm{mM}$ $\mathrm{NaCl}, 1 \%(\mathrm{v} / \mathrm{v})$ Triton X-100, 1\% (w/v) sodium deoxycholate, and $0.1 \%(\mathrm{w} / \mathrm{v})$ SDS and protease inhibitors). Cell lysates were incubated with the following primary antibodies at a concentration of $5 \mu \mathrm{g} / \mathrm{ml}$ : Rabbit anti-human ANXA4 antibody (cat. no. ab153883) and rabbit anti-human NF- $\mathrm{B}$ p50 antibody (cat. no. ab264235; both purchased from Abcam), and Protein A/G plus-agarose (cat. no. sc-2003; Santa Cruz Biotechnology, Inc.) overnight at $4^{\circ} \mathrm{C}$. Normal rabbit IgG (5 $\mu \mathrm{g} / \mathrm{ml}$; cat. no. ab172730; Abcam) was used as the negative control. The immunoprecipitated proteins were separated via $10 \%$ SDS-PAGE gels and detected using rabbit anti-human ANXA4 antibody (1:1,000; cat. no. ab153883; Abcam) and rabbit anti-human NF- $\kappa \mathrm{B}$ p50 antibody (1:1,000; cat. no. ab264235; Abcam) overnight at $4^{\circ} \mathrm{C}$. Protein bands were visualized using enhanced chemiluminescence (ECL) reagent (Amersham; Cytiva).

Confocal laser scanning microscopy. Monolayered cell slides were prepared using ES-2 cells. Cells were fixed with $100 \%$ methanol for $45 \mathrm{~min}$ at room temperature and stained with the following primary antibodies: Mouse anti-human ANXA4 antibody (1:100; cat. no. sc-46693; Santa Cruz Biotechnology, Inc.) and rabbit anti-human NF- $\mathrm{B}$ p50 antibody (1:100; cat. no. ab264235; Abcam) overnight at $4^{\circ} \mathrm{C}$. Following the primary incubation, cells were incubated with secondary antibodies FITC green fluorescence-labeled mouse IgG (1:50; cat. no. sc-2010; Santa Cruz Biotechnology, Inc.) and TRITC red fluorescence-labeled rabbit IgG (1:50; cat. no. sc-2492; Santa Cruz Biotechnology, Inc.) at room temperature for $1 \mathrm{~h}$. Cells were washed three times with PBS and cell nuclei were stained using DAPI (cat. no. sc-3598, Santa Cruz Biotechnology, Inc.) at a final concentration of $5 \mu \mathrm{g} / \mathrm{ml}$ for $5 \mathrm{~min}$ at $37^{\circ} \mathrm{C}$. Fluorescent images were visualized under by a laser confocal microscope (C1-SI; Nikon, Corporation, magnifications x200 and x400). PBS was used as the negative control instead of the primary antibodies.

Western blotting. Briefly, the cells (ES-2-A4-O, ES-2, RMG-1-A4-I, and RMG-1 cells) were washed twice with ice-cold PBS, and total protein was extracted on ice using radioimmunoprecipitation assay lysis buffer (cat. no. P0013B; Beyotime Institute of Biotechnology). Lysates were cleared by centrifugation $\left(15 \mathrm{~min}\right.$ at $\left.13,000 \mathrm{x} \mathrm{g}, 4^{\circ} \mathrm{C}\right)$. The protein content was measured using the protein assay BCA kit (Beyotime Institute of Biotechnology). Following quantitative analysis, equal amounts of protein $(50 \mu \mathrm{g})$ were resolved with $10 \%$ SDS-PAGE and electrotransferred onto polyvinylidene difluoride membranes. The membranes were blocked with Tris-buffered saline Tween [25 mM Tris- $\mathrm{HCl}, 150 \mathrm{mM} \mathrm{NaCl}$ (pH 7.5), and $0.1 \%$ Tween-20] containing 5\% non-fat milk at room temperature for $2 \mathrm{~h}$ and incubated overnight at $4^{\circ} \mathrm{C}$ with the following primary antibodies: Mouse anti-human ANXA4 (1:1,000; cat. no. sc-46693; Santa Cruz Biotechnology, Inc.), rabbit anti-human NF- $\mathrm{B}$ p50 (1:200; cat. no. ab264235; Abcam), mouse anti-human Bcl-2 (1:1,000; cat. no. 15071; Cell Signaling Technology, CST, Co., USA) and rabbit anti-human Cyclin D1 (1:1,000; cat. no. 55506; Cell signaling technology) in TTBS $/ 1 \%$ non-fat milk. Following three washes with TTBS, the membranes were incubated with the appropriate horseradish peroxidase-linked IgG (goat anti-mouse IgG-HRP, 
cat. no. sc-2005, 1:2,000 and goat anti-rabbit IgG-HRP, cat. no. sc-2004, 1:2,000; Santa Cruz Biotechnology, Inc.) at room temperature for $1 \mathrm{~h}$, and visualization using an ECL (Pierce; Thermo Fisher Scientific, Inc.) detection system. The western blots shown are representative of at least 3 independent experiments. The protein bands were visualized using the Molecular Imager system GDS8000b (Analytik Jena AG). Total protein levels were normalized to GAPDH $(1: 2,000$; cat. no. sc-47724; Santa Cruz Biotechnology, Inc.) expression on the same membrane, and the bands were quantified using ImageJ software v1.8.0 (National Institutes of Health).

Immunocytochemistry. Monolayered cell slides were prepared using ES-2, ES-2-A4-O, RMG-1 and RMG-1-A4-I cells, while they were in the exponential growth phase. The expression of ANXA4 and NF- $\kappa$ B p50 in the cells was detected according to the instructions provided with the SABC kit (cat. no. SA1054; Boster Biological Technology Co., Ltd.). Briefly, the cells were fixed with $4 \%$ paraformaldehyde for $30 \mathrm{~min}$ at room temperature, and the nonspecific antigens were blocked with $10 \%$ normal goat serum (cat. no. AR0009; Boster Biological Technology Co., Ltd.) for $30 \mathrm{~min}$ at room temperature. The cells were incubated with primary antibodies overnight at $4^{\circ} \mathrm{C}$. Following rinsing with PBS three times, the cells were incubated with secondary antibody (horseradish peroxidase-conjugated goat anti-rabbit immunoglobulin G; 1:500; cat. no. sc-2004; Santa Cruz Biotechnology, Inc.) for $30 \mathrm{~min}$ at room temperature. The following primary antibodies were used: Rabbit anti-human ANXA4 (1:100; cat. no. ab153883; Abcam) and rabbit anti-human NF-кB p50 (1:300; cat. no. ab264235; Abcam). The primary antibody was replaced by PBS for the negative control.

Treatment with $N F-\kappa B$ pathway inhibitor. The NF- $\kappa$ B pathway inhibitor, BAY 11-7082 (Sigma-Aldrich; Merck KGaA) was added to cells at a concentration of $5 \mu \mathrm{mol} / \mathrm{ml}$, and proteins were collected after $24 \mathrm{~h}$.

Growth inhibition assay. Cell viability was assessed via the MTT assay. Briefly, 6×10³ cells were seeded into 96-well plates and cultured in RPMI-1640 medium or Macoy $5 \mathrm{~A}$ supplemented with $10 \% \mathrm{FBS}$, respectively, at $37^{\circ} \mathrm{C}$ in $5 \% \mathrm{CO}_{2}$ overnight. After $24 \mathrm{~h}$, the cells were treated with serum-free media supplemented with BAY 11-7082 (Sigma-Aldrich; Merck KGaA). A total of four cell lines were assessed: ES-2, ES-2-A4-O, ES-2-A4-O+BAY 11-2078 and ES-2+BAY 11-2078. The 0 point was achieved after $6 \mathrm{~h}$ of cell culture, and optical density (OD) was measured at the 0 point after 24, 48 and $72 \mathrm{~h}$. Following the different durations of treatment, the cells were incubated with $20 \mu \mathrm{l}$ MTT $(5 \mathrm{mg} / \mathrm{ml}$; Sigma-Aldrich; Merck KGaA) for $4 \mathrm{~h}$ at $37^{\circ} \mathrm{C}$. The supernatant was removed, the purple formazan crystals were dissolved using $150 \mu \mathrm{l}$ dimethyl sulfoxide (DMSO) and viability was subsequently analyzed at a wavelength of $570 \mathrm{~nm}$ using a 96-well multiscanner autoreader (Bio-Rad Laboratories, Inc.).

Flow cytometric analysis of apoptosis. Cell apoptosis was assessed via flow cytometric analysis of the ES-2, ES-2-A4-O and ES-2-A4-O+BAY 11-2078 cell lines. Cells were double stained with allophycocyanin (APC) annexin $\mathrm{V}$ conjugate (Annexin V-APC) and propidium iodide (PI), using the
Annexin V-APC/PI kit (Nanjing KeyGen Biotech Co., Ltd.) for $10 \mathrm{~min}$ at room temperature away from light, according to the manufacturer's protocol. Blanks were run as controls for both PI and Annexin V-APC staining, for each group. Apoptotic cells were subsequently analyzed using a flow cytometer (BD FACSCanto II; BD Biosciences) and Cell Quest program (version 6.0; FACScan; BD Biosciences). All experiments were performed in triplicate.

PPI network of ANXA4, NF- $\kappa B$ p50 and p53. The PPI network was constructed using the cBioPortal database (http://www. cbioportal.org) and visualized using Cytoscape software version 3.7.2 (24). And confidence score $\geq 0.4$ was set as the cut-off criterion.

Functional and signaling pathway enrichment analysis. Gene Ontology (GO) and Kyoto Encyclopedia of Genes and Genomes (KEGG; http://www.kegg.jp) analyses were performed for functional annotation and pathway assessment, using the Database for Annotation Visualization and Integrated Discovery (DAVID) (http://david.abcc.ncifcrf.gov). The human genome was selected as the background parameter. $\mathrm{P}<0.05$ and a count $\geq 2$ were set as the thresholds to indicate a statistically significant difference.

Statistical analysis. Statistical analysis was performed using SPSS 17.0 software (SPSS, Inc.). Data are presented as the mean \pm standard deviation. The $\chi^{2}$ test was used to assess the positive ratio rates. Pearson's $\chi^{2}$ test was used to determine the association between ANXA4 and NF- $\mathrm{B}$ p50 (or mutant p53). Survival analysis was performed using Kaplan-Meier curves, and significant differences among different clinicopathological variants and immunomarkers were determined using the log-rank test. Cox proportional hazards regression model was used to control for confounding variables. Unpaired Student's t-test was performed to compare differences between two groups, while one-way analysis of variance and Least Significant Difference or Bonferroni post hoc tests were used to compare differences between multiple groups. All the experiments were performed in triplicate. $\mathrm{P}<0.05$ was considered to indicate a statistically significant difference.

\section{Results}

Nuclear expression of ANXA4 and NF- $\kappa B$ p50 in different ovarian tissues. The positive expression of ANXA4 was observed throughout the cell membrane, cytoplasm and nucleus in different ovarian tissues. The positive nuclear expression of ANXA4 in OCCC was $77.9 \%$, which was significantly higher compared with the three subtypes (serous, mucinous and endometrioid) of OC (27.3\%) and normal ovarian tissues $(0 \%)$. The strong positive ('++' and ' +++ ' represent strong positive expression) nuclear expression of ANXA4 in OCCC was $38.3 \%$ (33/86), which was markedly greater compared with the three subtypes of OC $(9.1 \%, 5 / 55)$ and normal ovarian tissues (0\%) (Fig. 1 and Table I).

$\mathrm{NF}-\kappa \mathrm{B}$ p50 was predominantly expressed in the nucleus and the cytoplasm. The positive nuclear expression of $\mathrm{NF}-\kappa \mathrm{B}$ p50 in OCCC was $97.7 \%$, which was significantly higher compared with the three subtypes of OC (65.5\%) and normal ovarian tissues $(0 \%)$. The strong positive nuclear expression 
Table I. Nuclear expression of ANXA4 and NF-кB p50 in different ovarian tissues.

\begin{tabular}{|c|c|c|c|c|c|c|c|c|c|c|c|c|c|c|c|}
\hline \multirow[b]{2}{*}{ Characteristic } & \multirow[b]{2}{*}{$\begin{array}{c}\text { Number } \\
\text { of cases, } \\
n\end{array}$} & \multicolumn{6}{|c|}{ ANXA4 } & \multirow[b]{2}{*}{ P-value } & \multicolumn{6}{|c|}{ NF- $\kappa B$ p50 } & \multirow[b]{2}{*}{ P-value } \\
\hline & & - & + & ++ & +++ & $\begin{array}{c}\text { Positive } \\
\text { n (\%) }\end{array}$ & $\begin{array}{l}\text { Strong } \\
\text { positive } \\
\mathrm{n}(\%)\end{array}$ & & - & + & ++ & +++ & $\begin{array}{c}\text { Positive } \\
\text { n (\%) }\end{array}$ & $\begin{array}{l}\text { Strong } \\
\text { positive } \\
\mathrm{n}(\%)\end{array}$ & \\
\hline Normal & 10 & 10 & 0 & 0 & 0 & $0\left(0^{b}\right)$ & $0\left(0^{b}\right)$ & $<0.001$ & 10 & 0 & 0 & 0 & $0\left(0^{\mathrm{d}}\right)$ & $0\left(0^{\mathrm{d}}\right)$ & $<0.001$ \\
\hline OCCC & 86 & 19 & 34 & 15 & 18 & $67\left(77.9^{\mathrm{a}}\right)$ & $33\left(38.3^{\mathrm{a}}\right)$ & $<0.001$ & 2 & 34 & 32 & 18 & $84\left(97.7^{c}\right)$ & $50\left(58.1^{c}\right)$ & $<0.001$ \\
\hline Other subtypes & 55 & 40 & 10 & 2 & 3 & $15(27.3)$ & $5(9.1)$ & & 19 & 23 & 8 & 5 & $36(65.5)$ & $13(23.6)$ & \\
\hline Serous & 30 & 25 & 4 & 0 & 1 & $5(8.3)$ & $1(3.3)$ & & 10 & 14 & 4 & 2 & $20(66.7)$ & $6(20.0)$ & \\
\hline Mucinous & 17 & 9 & 5 & 1 & 2 & $8(47.1)$ & $3(17.6)$ & & 8 & 6 & 2 & 1 & $9(52.9)$ & $3(17.6)$ & \\
\hline Endometrioid & 8 & 6 & 1 & 1 & 0 & $2(25.0)$ & $1(12.5)$ & & 1 & 3 & 2 & 2 & 7 (87.5) & $4(50.0)$ & \\
\hline
\end{tabular}

${ }^{\mathrm{a}, \mathrm{c}}$ Comparison of the expression of ANXA4 and NF- $\mathrm{kB}$ p50 in OCCC and other OC subtypes. ${ }^{\mathrm{b}, \mathrm{d}}$ Comparison of the expression of ANXA4 and NF- $\mathrm{BB}$ p50 in OCCC and normal ovarian tissue. ANXA4, Annexin IV; NF- $\kappa$ B, nuclear factor- $\kappa$-light-chain-enhancer of activated B cells; OCCC, ovarian clear cell carcinoma.
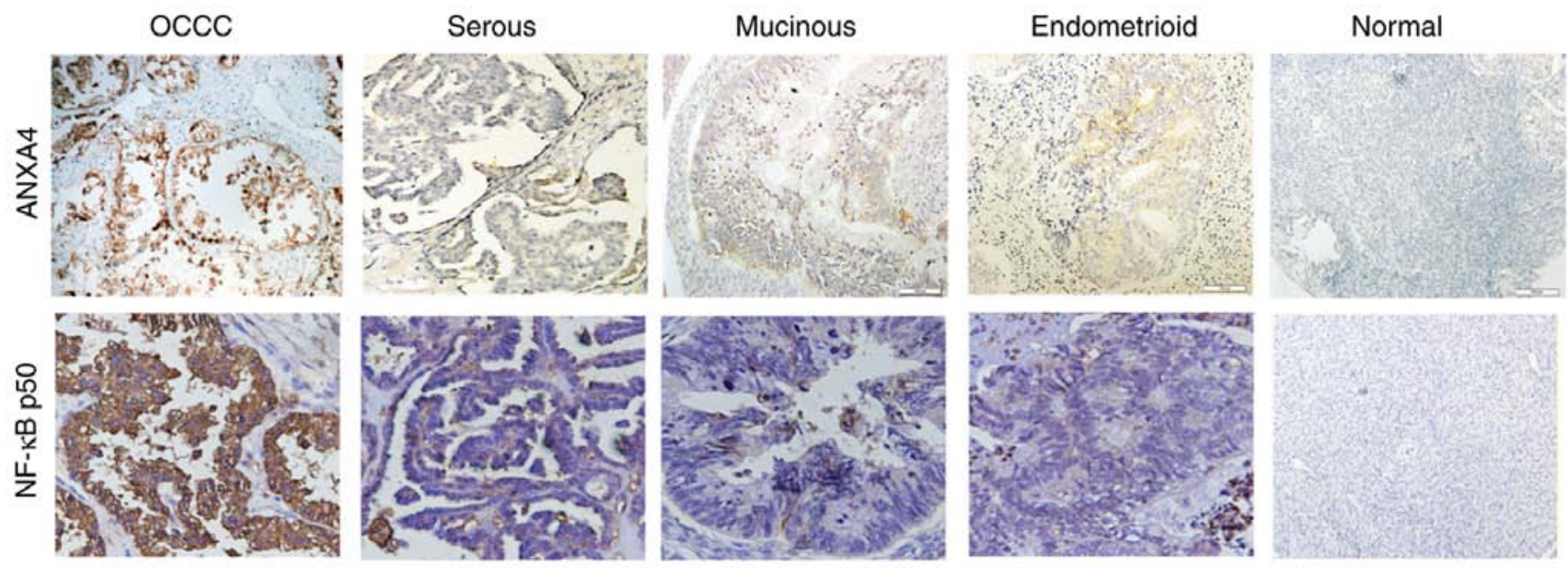

Figure 1. Nuclear expression of ANXA4 and NF-кB p50 in different ovarian tissues. Immunohistochemistry was performed to detect ANXA4 and NF- $\mathrm{kB}$ p50 expression in normal ovarian tissues and tissues from different subtypes of ovarian cancer (magnification $\mathrm{x} 400$ ). OCCC, ovarian clear cell carcinoma; ANXA4, Annexin IV; NF-kB, nuclear factor-k-light-chain-enhancer of activated B cells.

of NF-kB p50 in OCCC was 58.1\% (50/86), which was markedly greater compared with the three subtypes of OC $(23.6 \%$, 13/55) and normal ovarian tissues (0\%) (Fig. 1 and Table I).

Association between the nuclear expression of ANXA4 and $N F-\kappa B \quad p 50$, and the clinicopathological characteristics of $O C C C$. As presented in Table II, the strong positive nuclear expression of ANXA4 in FIGO advanced stage OCCC (III-IV stage) was $55.6 \%$, which was significantly higher compared with FIGO early stage OCCC (I-II stage; $30.5 \%$; $\mathrm{P}=0.0266)$. The strong positive nuclear expression of ANXA4 in the chemotherapeutics-resistant group was $68.4 \%$, which was significantly higher compared with the chemotherapeutics-sensitive group (30.8\%; $\mathrm{P}=0.0043)$. No significant difference in the positive nuclear expression of ANXA4 was observed between the lymph node metastasis groups (60.0\% vs. $33.8 \%)$.

Similarly, the strong positive nuclear expression of NF-кB p50 in FIGO advanced stage OCCC was $74.1 \%$, which was significantly higher compared with FIGO early stage OCCC (50.8\%; $\mathrm{P}=0.0427)$. In addition, the strong positive nuclear expression of NF- $\kappa \mathrm{B}$ p50 in the chemotherapeutics-resistant group was $84.2 \%$, which was significantly higher compared with the chemotherapeutics-sensitive group $(48.1 \% ; \mathrm{P}=0.0064)$. No significant difference in the strong positive nuclear expression of NF- $\kappa \mathrm{B}$ p50 was observed between the lymph node metastasis groups (80.0 vs. $54.1 \%$ ) (Table II).

High nuclear expression of ANXA4 and NF- $\mathrm{B}$ p 50 in OCCC predicts a poor prognosis. A total of 86 patients with OCCC were followed up (36-108 months). By December 2015, 75 cases completed follow-up, while 11 cases were lost to follow-up (because the patients and their families refused contact during the follow-up.). As presented in Fig. 2, in the high ANXA4 nuclear expression group $(\mathrm{n}=29), 14$ cases died and the mean survival time was 39.1 months, while in the low ANXA4 nuclear expression group $(\mathrm{n}=46), 10$ cases died and the mean survival time was 48.1 months. In the high NF- $\mathrm{BB}$ p50 nuclear expression group $(n=43), 20$ cases died and the mean survival time was 40 months, while in the low NF- $\mathrm{KB}$ p50 nuclear expression group $(\mathrm{n}=32)$, four cases died and the mean survival time was 50.8 months. 
Table II. Association between the nuclear expression of ANXA4 and NF- $\mathrm{BB}$ p50 and the clinicopathological characteristics of ovarian clear cell carcinoma.

\begin{tabular}{|c|c|c|c|c|c|c|c|}
\hline \multirow[b]{2}{*}{ Characteristic } & \multirow{2}{*}{$\begin{array}{c}\text { Number of } \\
\text { cases, } \mathrm{n}\end{array}$} & \multicolumn{2}{|c|}{ ANXA4 expression } & \multirow[b]{2}{*}{ P-value } & \multicolumn{2}{|c|}{ NF-кB p50 expression } & \multirow[b]{2}{*}{ P-value } \\
\hline & & Low, $\mathrm{n}$ & High, n & & Low, n & High, n & \\
\hline \multicolumn{8}{|l|}{ Surgical stage } \\
\hline I-II & 59 & 41 & 18 & 0.0266 & 29 & 30 & 0.0427 \\
\hline III-IV & 27 & 12 & 15 & & 7 & 20 & \\
\hline \multicolumn{8}{|c|}{ Lymph node metastasis } \\
\hline Yes & 10 & 4 & 6 & 0.2064 & 2 & 8 & 0.2241 \\
\hline No & 74 & 49 & 25 & & 34 & 40 & \\
\hline \multicolumn{8}{|c|}{ Chemosensitivity } \\
\hline Sensitive & 52 & 36 & 16 & 0.0043 & 27 & 25 & 0.0064 \\
\hline Resistant & 19 & 6 & 13 & & 3 & 16 & \\
\hline
\end{tabular}

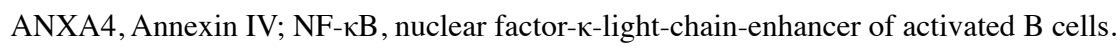
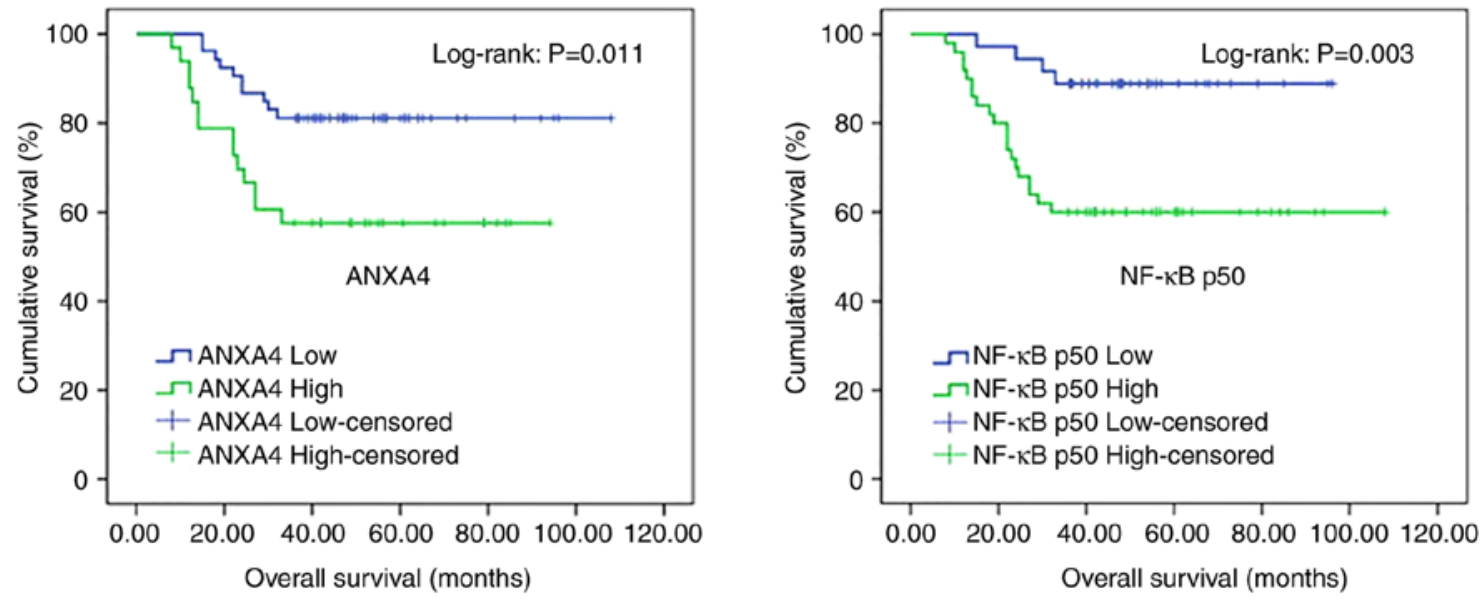

Figure 2. The association between ANXA4 and NF-кB p50 expression on the survival time of patients with ovarian clear cell carcinoma. Kaplan-Meier survival analysis demonstrated that high expression levels of ANXA4 and NF- $\mathrm{kB}$ p50 were independent risk factors for overall survival. ANXA4, Annexin IV; NF- $\mathrm{KB}$, nuclear factor- $\kappa$-light-chain-enhancer of activated B cells.

Survival rates of patients with OCCC were evaluated via Kaplan-Meier analysis, which indicated that the prognosis was significantly unfavorable in the high ANXA4 and NF- $\mathrm{kB}$ p50 nuclear expression groups compared with the respectively low ANXA4 and NF- $\mathrm{KB}$ p50 nuclear expression groups $(\mathrm{P}=0.011$ and $\mathrm{P}=0.003$; Fig. 2).

Multivariate analysis of OCCC prognosis was performed using the Cox proportional hazards regression model. The FIGO stage, residual tumor size, lymph node metastasis status, age and expression levels of ANXA4 and NF- $\mathrm{kB}$ p50 were included in the dependent variable analysis. The results demonstrated that the advanced FIGO stage, and high expression levels of ANXA4 and NF- $\mathrm{kB}$ p50 were independent risk factors for the prognosis of patients with OCCC $(\mathrm{P}=0.007$, $\mathrm{P}=0.042$ and $\mathrm{P}=0.015$; Table III).

Nuclear expression of ANXA4, NF- $\kappa B$ p50 and mutant p53 in $O C C C$. A previous study reported that ANXA4 expression in OCCC is closely associated with p53 (18). Thus, the present study assessed mutant p53 expression in OCCC. The results demonstrated that mutant p53 was primarily localized in the cell nucleus. However, as presented in Fig. 3, mutant p53 expression was rarely seen in OCCC tissues, and the expression levels were very low. In contrast to mutant $\mathrm{p} 53$, the expression levels of ANXA4 and NF-kB p50 were generally enhanced in OCCC tissues.

Analysis of the correlation between ANXA4 and NF- $\kappa B$ p50 nuclear expression in OCCC. Of the 86 OCCC tissue samples, high ANXA4 and NF- $\mathrm{kB}$ p50 nuclear co-expression was observed in 24 cases, while low ANXA4 and NF- $\mathrm{BB}$ p50 nuclear co-expression was observed in 28 cases. ANXA4 and NF- $\kappa \mathrm{B}$ p50 expression levels exhibited a linear correlation $\left(\chi^{2}=5.95, P=0.015\right.$; Table IV $)$.

Analysis of the association between mutant p53 and ANXA4 expression in OCCC. Of the 86 OCCC tissue samples, 16 cases had positive p53 expression and 70 cases had negative p53 
Table III. Cox regression analysis of overall survival of ovarian clear cell carcinoma.

\begin{tabular}{lcl}
\hline Variable & P-value & Hazard ratio (95\% CI) \\
\hline ANXA4 (high vs. low) & 0.042 & $2.367(1.030-5.438)$ \\
NF-кB p50 (high vs. low) & 0.015 & $3.894(1.302-11.644)$ \\
Surgical stage (III-IV vs. I-II) & 0.007 & $3.783(1.432-9.991)$
\end{tabular}

ANXA4, Annexin IV; NF- $\kappa$ B, nuclear factor- $\kappa$-light-chain-enhancer of activated $B$ cells.

Table IV. Correlation between ANXA4 and NF- $\mathrm{B}$ p50 expression in ovarian clear cell carcinoma.

\begin{tabular}{|c|c|c|c|c|c|}
\hline \multirow{2}{*}{$\begin{array}{l}\text { NF-кB p50 } \\
\text { expression }\end{array}$} & \multicolumn{2}{|c|}{$\begin{array}{c}\text { ANXA4 } \\
\text { expression }\end{array}$} & \multirow[b]{2}{*}{ Total, $\mathrm{n}$} & \multirow[b]{2}{*}{ P-value } & \multirow[b]{2}{*}{$\chi^{2}$} \\
\hline & High & Low & & & \\
\hline High & 24 & 26 & 50 & 0.015 & 5.95 \\
\hline Low & 8 & 28 & 36 & & \\
\hline Total & 32 & 54 & 86 & & \\
\hline
\end{tabular}

ANXA4, Annexin IV; NF- $\kappa$ B, nuclear factor- $\kappa$-light-chain-enhancer of activated $B$ cells.

Table V. Association between ANXA4 and mutant p53 expression in ovarian clear cell carcinoma.

\section{ANXA4}

expression

Mutant p53

expression Positive Negative Total, $\mathrm{n}$ P-value $\chi^{2}$

\begin{tabular}{lrllll}
\hline Negative & 31 & 39 & 70 & 0.018 & 5.56 \\
Positive & 2 & 14 & 16 & & \\
Total & 33 & 53 & 86 & & \\
\hline
\end{tabular}

ANXA4, Annexin IV.

expression. Mutant p53 expression was observed in two cases with high ANXA4 expression and 14 cases with low ANXA4 expression. No mutant p53 expression was exhibited in 31 cases with high ANXA4 expression and 39 cases with low ANXA4 expression. A linear association was observed between $\mathrm{p} 53$ and ANXA4 expression levels $\left(\chi^{2}=5.56 ; \mathrm{P}=0.018\right.$; Table V).

ANXA4 and NF- $\mathrm{NB}$ p50 are co-expressed in OCCC. Co-immunoprecipitation analysis demonstrated that there was an interaction between ANXA4 and NF- $\kappa \mathrm{B}$ p50 expression in human OCCC derived RMG-1 and ES-2 cell lines (Fig. 4A). Laser scanning confocal microscopy confirmed the co-localization of ANXA4 and NF- $\kappa$ B p50 in OCCC cells (Fig. 4B). Western blot and immunocytochemical analyses demonstrated that both ANXA4 and NF- $\mathrm{B}$ p50 expression in established
ES-2-A4-O cells increased compared with ES-2 cells following transfection of ANXA4 gene in ES-2 cells. Furthermore, $\mathrm{NF}-\kappa \mathrm{B}$ p50 expression (when the ANXA4 gene was silenced in RMG-1 cells), and the expression levels of ANXA4 and NF- $\mathrm{B}$ p50 significantly decreased in RMG-1-A4-I cells compared with RMG-1 cells, following transfection (Fig. 4C and D). Taken together, these results suggest that ANXA4 and NF-кB p50 are interacting proteins, and their interaction may be enhanced by upregulating ANXA4 expression.

PPI network construction and module selection. As presented in Fig. 5, the PPI network of the differentially expressed genes consisted of 50 nodes and 219 edges. ANXA4, NFkB1 (the precursor of $\mathrm{NF}-\kappa \mathrm{B}$ p50), and TP53 were demonstrated to regulate each other, whilst forming complex regulatory associations with other genes, such as MYC and BCL2L1.

Function and signaling pathway enrichment analysis. Function and pathway enrichment analysis of related genes in the PPI network was performed using DAVID database. The results demonstrated that pathways with related genes were enriched in 'NF- $\mathrm{B}$ signaling pathway', 'apoptosis', 'cell cycle', 'PI3K/Akt signaling pathway' and 'MAPK signaling pathway' (Fig. 6A). These genes are predominantly involved in 'biological processes', including 'negative regulation of apoptotic process', 'regulation of cell proliferation', 'cell cycle arrest' and 'NIK/NF- $\mathrm{BB}$ signaling' (Fig. 6B).

Interaction between ANXA4 and NF- $\kappa B$ p50 promotes cell proliferation and inhibits cell apoptosis. The expression of Cyclin D1 and Bcl-2 (downstream molecules of the NF- $\kappa \mathrm{B}$ signaling pathway) in ES-2 cells was detected via western blotting after the ES-2 cells were transfected with the ANXA4 gene and added to the $\mathrm{NF}-\kappa \mathrm{B}$ inhibitor, respectively. The results demonstrated that the expression levels of both Cyclin D1 and Bcl-2 increased following transfection of the ANXA4 gene; however, these levels decreased after $24 \mathrm{~h}$, following addition of the NF- $\kappa \mathrm{B}$ inhibitor (Fig. 7A). Collectively, these results indicate that the interaction between

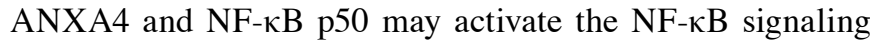
pathway, and promote Cyclin D1 and Bcl-2 expression.

The changes in the capacity of cell proliferation and apoptosis before and after transfection of the ANXA4 gene, and addition of the NF- $\mathrm{NB}$ inhibitor were further assessed via the MTT assay and flow cytometric analysis. The results demonstrated that the proliferation capacity increased (ES-2 compared with $\mathrm{ES}-2-\mathrm{A} 4-\mathrm{O}, \mathrm{P}=0.032$ ) and cell apoptosis decreased (ES-2 compared with ES-2-A4-O, $\mathrm{P}=0.041)$ following transfection of the ANXA4 gene; however, this effect was significantly reversed after $24 \mathrm{~h}$, following addition of the $\mathrm{NF}-\kappa \mathrm{B}$ inhibitor, BAY 11-2078 (5 $\mu \mathrm{mol} / \mathrm{ml}$; Fig. 7B and C; ES-2-A4-O compared with ES-2-A4-O + BAY 11-2078, $\mathrm{P}=0.017$ and $\mathrm{P}=0.008$, respectively). Taken together, these results suggest that the interaction between ANXA4 and NF- $\kappa \mathrm{B}$ p50 may activate the $\mathrm{NF}-\kappa \mathrm{B}$ signaling pathway, whilst promoting the proliferation and inhibiting the apoptosis of OCCC cells.

\section{Discussion}

OCCC is a type of ovarian epithelial carcinoma that currently lacks effective therapies due to lack of knowledge regarding 

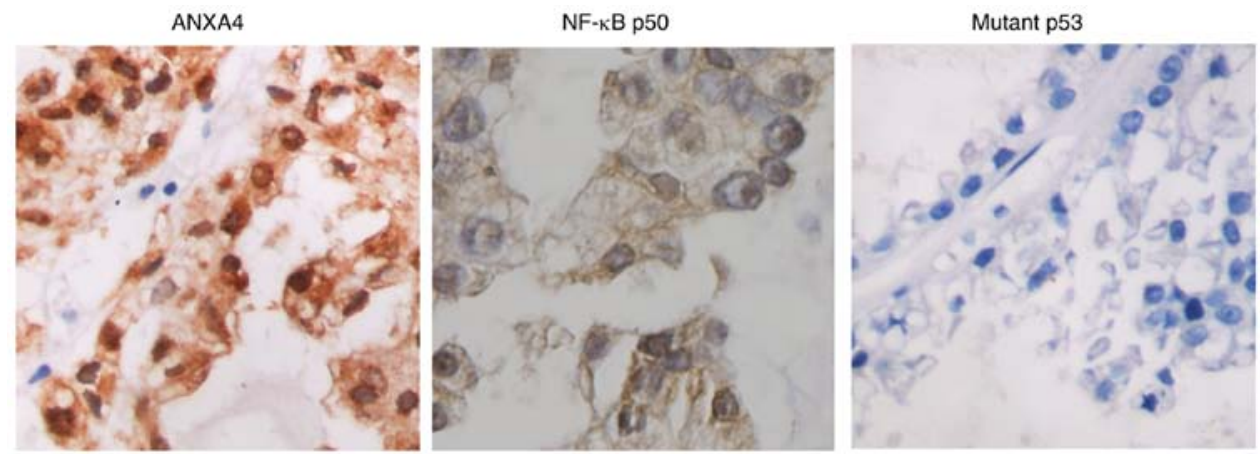

Figure 3. Expression levels of ANXA4, NF-кB p50 and mutant p53 in ovarian clear cell carcinoma tissues (magnification x400). ANXA4, Annexin IV;

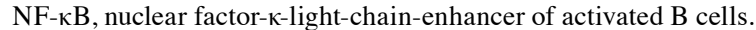

A

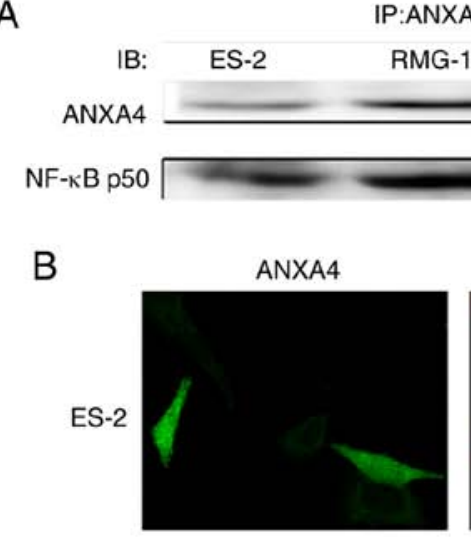

C
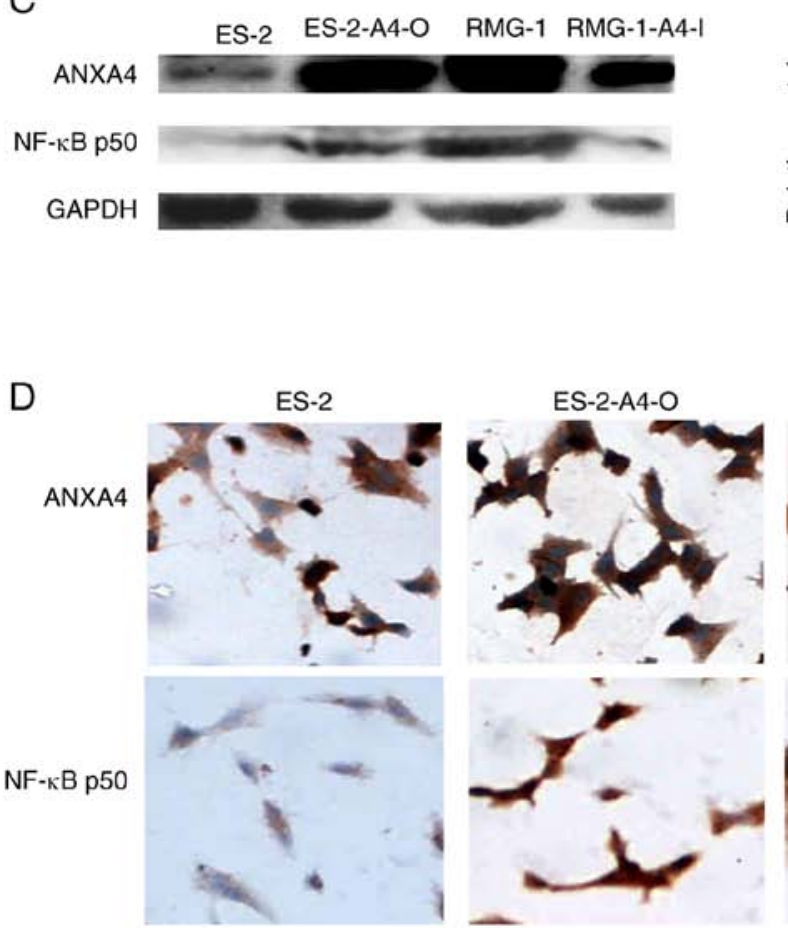

NF- $\mathrm{kB}$ p50

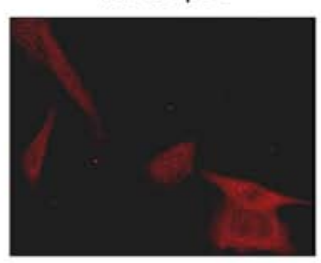

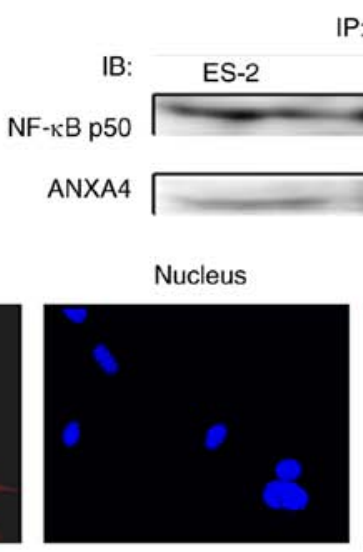

IP:NF-KB p50

RMG-1
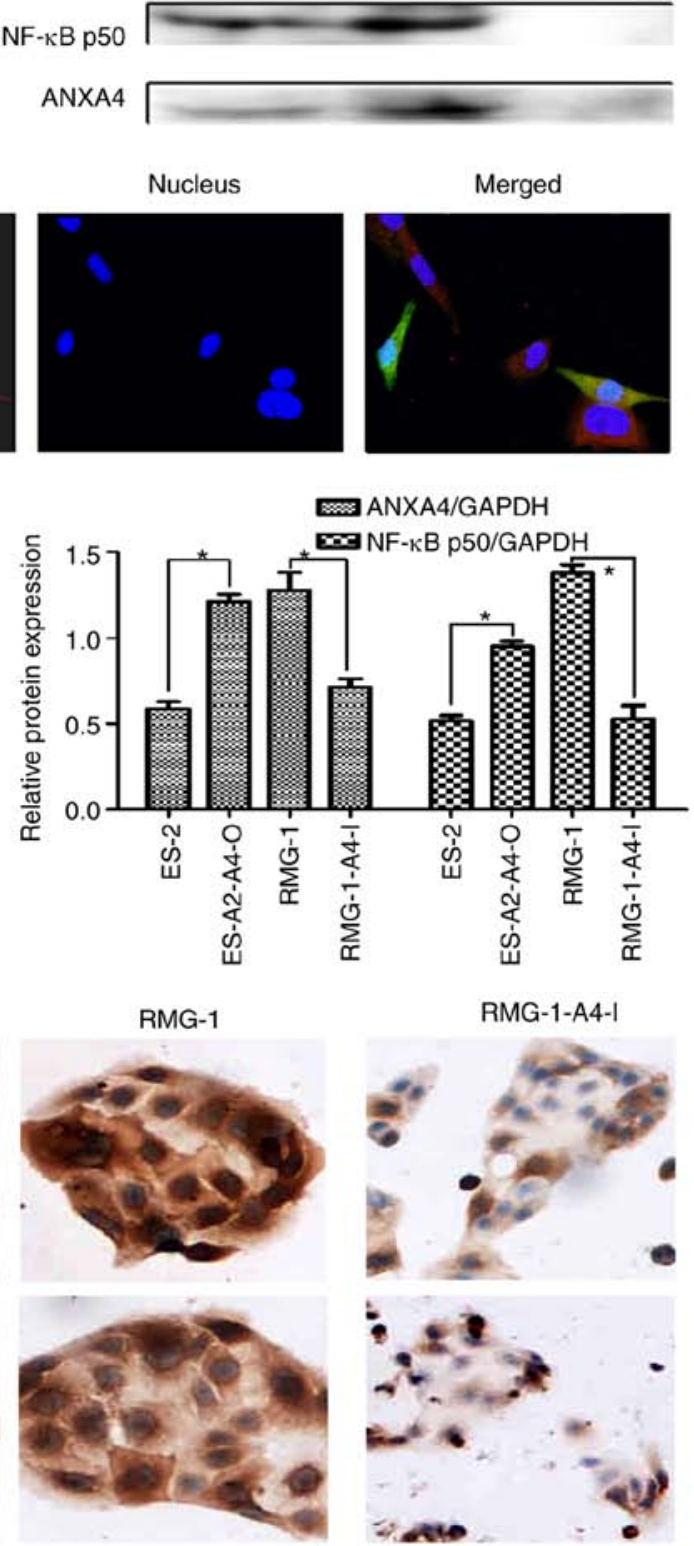

RMG-1-A4-I

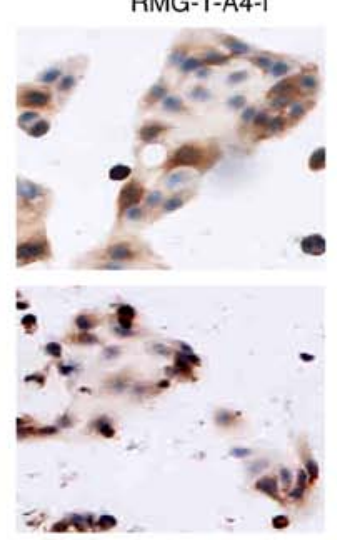

Figure 4. Interaction between ANXA4 and NF- $\mathrm{BB}$ p50 in OCCC cell lines. (A) Co-immunoprecipitation analysis was performed to determine the association between ANXA4 and NF- $\mathrm{B}$ p50. (B) Double-labeling immunofluorescence analysis demonstrated co-localization of ANXA4 and NF- $\mathrm{B}$ p50 in OCCC cells. (C) Western blot analysis was performed to detect ANXA4 and NF- $\kappa$ B p50 expression following transfection of the ANXA4 gene. (D) Immunocytochemistry

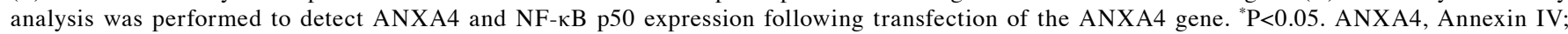
NF- $\kappa$ B, nuclear factor- $\kappa-$ light-chain-enhancer of activated B cells; OCCC, ovarian clear cell carcinoma; IB, immunoblotting; IP, immunoprecipitation; NOT, anti-IgG antibody (negative control). 


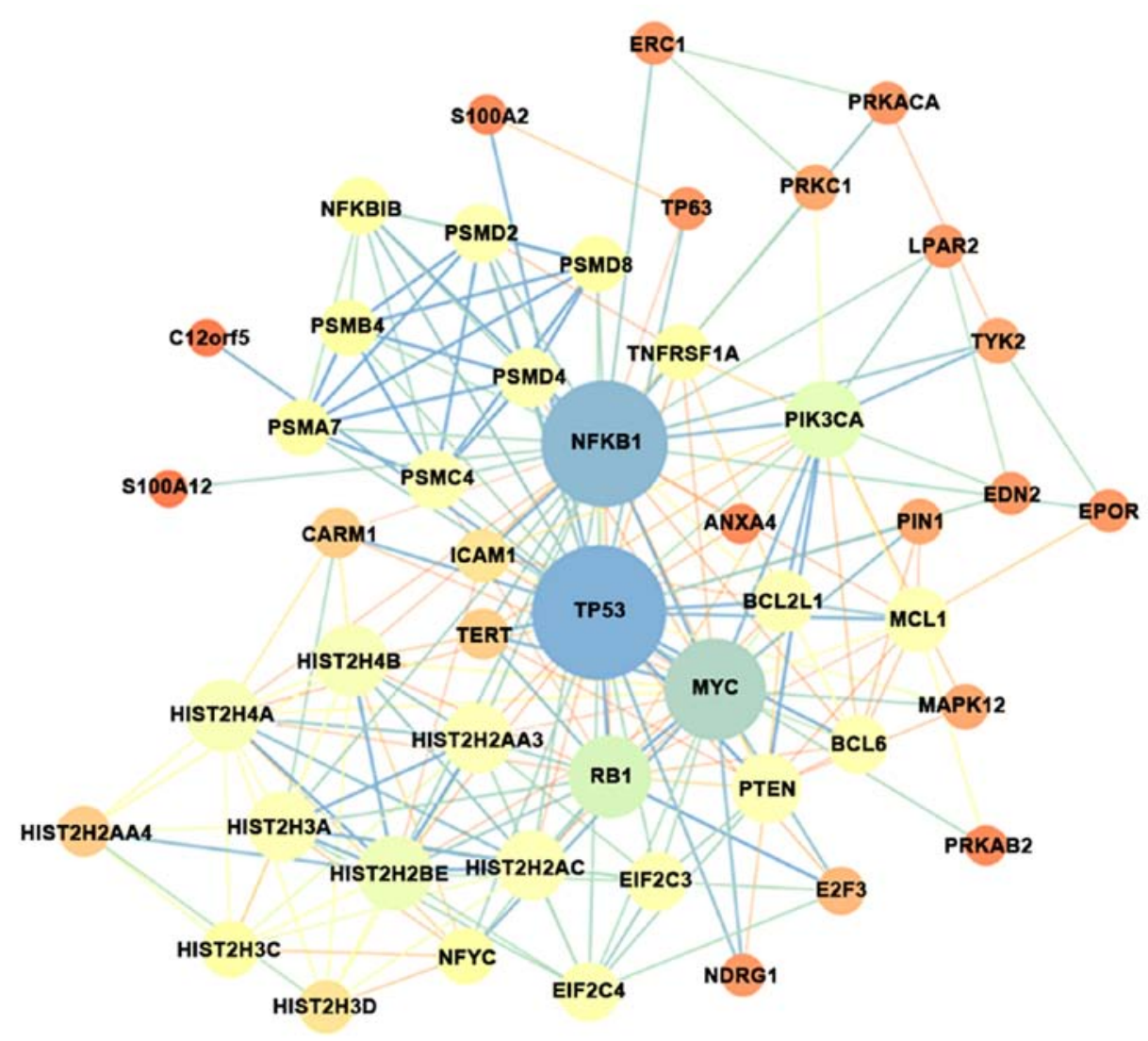

Figure 5. Protein-protein interaction network on ANXA4, NF-кB p50 and TP53 was constructed using Cbioportal database. Each node represents a protein, while the edges between the nodes represent the interaction between the proteins. The thickness of the line correlates to the strength of the association. The stronger the interaction between proteins, the more connectivity, the bigger the nodes and the darker the color.

the occurrence and developmental mechanisms. Its prognosis is unfavorable compared with other subtypes, such as serous and mucinous, and the 5-year survival rate is only $27 \%(25,26)$. A previous study has reported that ANXA4 is highly expressed in OCCC, while weakly expressed or even absent in other subtypes of ovarian epithelial carcinoma, thus, ANXA4 is considered a specific marker of OCCC (11). Subsequent studies have revealed that in the cervical cancer Hela cell line, ANXA4 can enter into the nucleus and influence the transcription of target genes and those associated with NF- $\kappa \mathrm{B}$ p50 (12). In order to determine the interaction between ANXA4 and NF- $\kappa$ B p50 in different pathological types of OC, the nuclear expression of ANXA4 and NF- $\mathrm{KB}$ p50 was assessed in different subtypes of ovarian epithelial carcinoma and normal ovarian tissues via IHC analysis. The results demonstrated that the positive nuclear expression (77.9, 97.7\%) and strong positive expression (38.3, 58.1\%) of ANXA4 and NF- $\kappa B$ p50 were both significantly higher in OCCC tissues compared with ANXA4 expression in other subtypes of ovarian epithelial carcinoma $(27.3,65.5 \% ; 9.1,23.6 \%)$ and normal ovarian tissues $(0,0 \% ; 0,0 \%)$. The nuclear expression of ANXA4 and NF- $\mathrm{KB}$ p50 demonstrated a linear correlation in OCCC tissues, and high ANXA4 and NF- $\mathrm{BB}$ p50 expression levels were associated with an advanced clinical stage and chemotherapeutic resistance of OCCC. Cox proportional hazards regression analysis demonstrated that high expression levels of both ANXA4 and NF- $\mathrm{KB}$ p50 were independent risk factors for the poor prognosis of OCCC. Collectively, these results suggest that ANXA4 and NF- $\kappa \mathrm{B}$ p50 may promote malignant progression, thus resulting in poor prognosis of patients with OCCC.

The structural association between ANXA4 and NF- $\mathrm{KB}$ p50 in OCCC cell lines was assessed via co-immunoprecipitation, and the results suggested that ANXA4 and NF- $\mathrm{\kappa B}$ p50 were structurally associated and their nuclear expression was co-localized. This confirms the interaction between ANXA4 and NF- $\kappa \mathrm{B}$ p50 in OCCC cell nuclei.

In mammals, five members of the NF- $\kappa \mathrm{B}$ family have been

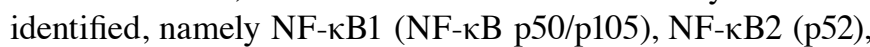
RelA (p65), RelB and C-Rel. In humans, NF- $\mathrm{KB}$ is predominantly expressed in the cytoplasm as a p65/p50 heterodimer and forms a NF- $\kappa \mathrm{B} / \mathrm{I} \kappa \mathrm{B}$-inactive trimer with I $\mathrm{KB}$ to hinder nuclear entry, thus preventing DNA-binding of NF- $\mathrm{KB}(27,28)$.

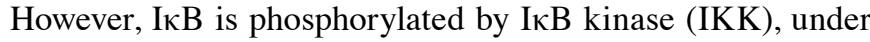
the stimulation of some factors, such as IL- $1 \beta$ and LPS, and subsequently degraded to activate NF- $\mathrm{kB}$ and its activation product, NF- $\mathrm{kB}$ p50 translocates to the nucleus from the cytoplasm, and binds with a DNA-specific $\kappa \mathrm{B}$ sequence to promote transcription and expression of a series of genes, including cytokines and growth factors, in different phases of several types of disease (29-31). Previous studies have suggested that overexpression of NF- $\mathrm{kB}$ as a nuclear transcription factor in tumor cells affects the progression of tumors mainly by the following mechanisms, upregulating cyclins or activating the expression of target genes and promoting cell proliferation, and inhibiting transduction of cell death signals and protecting 
A

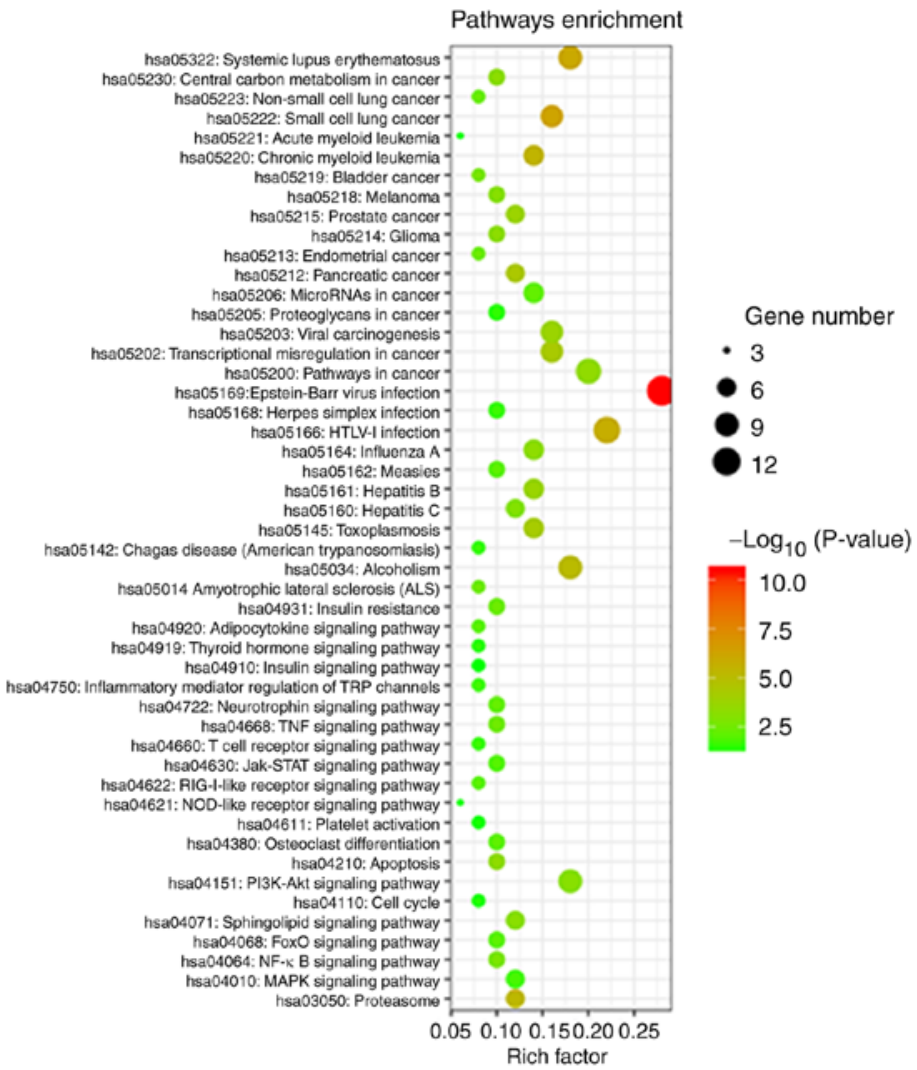

B

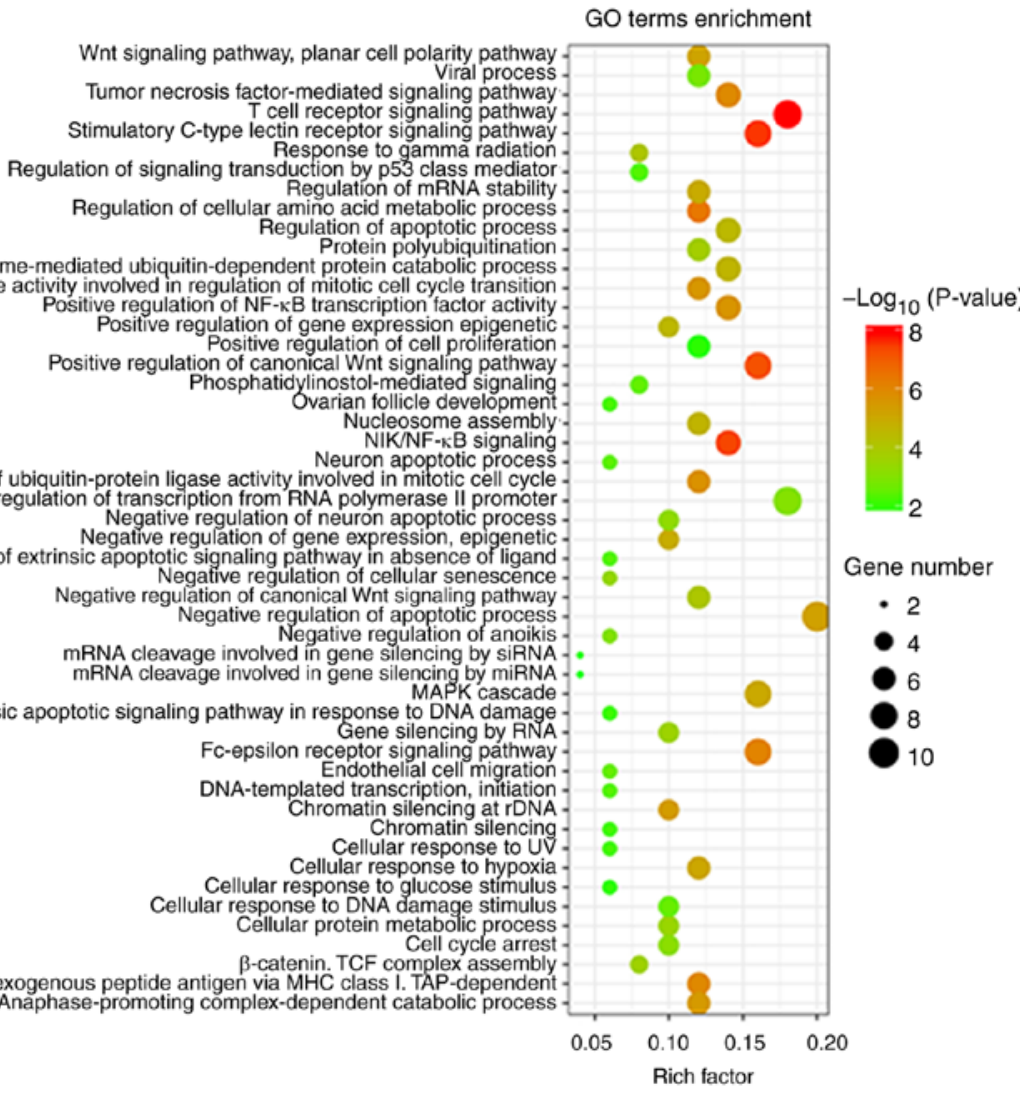

Figure 6. GO and signaling pathway enrichment analyses. (A) Signaling pathway bubble map. (B) Functional bubble map of gene enrichment in protein-protein interaction networks. The size of the bubble represents the number of genes in the signaling pathway or the number of genes involved in the function. Color represents P-value, the darker the color the more significant the result. GO, gene ontology.

cells from the induction of stimulating factors and the resultant apoptosis mechanisms $(32,33)$. Thus, this raises the question, does the interaction between ANXA4 and NF- $\mathrm{KB}$ p50 in OCCC cells influence the proliferation and apoptosis of tumor cells? 
A

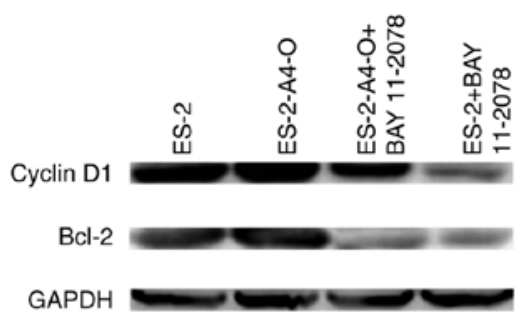

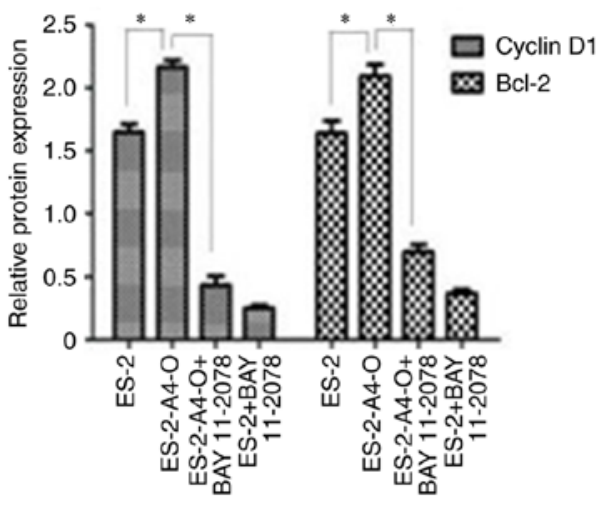

B

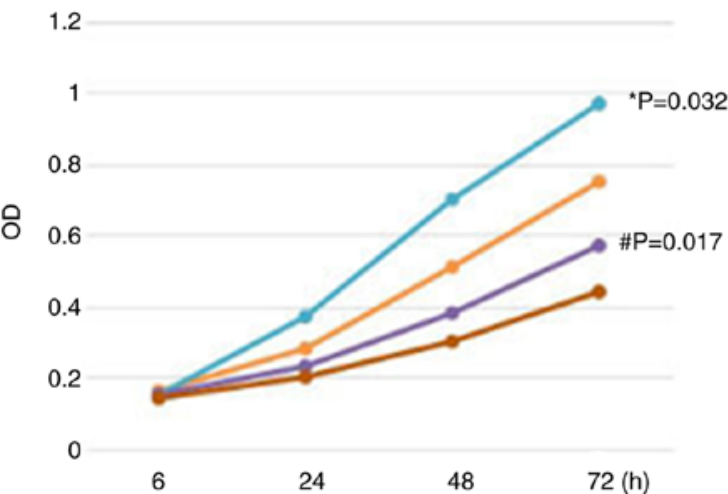

6

24

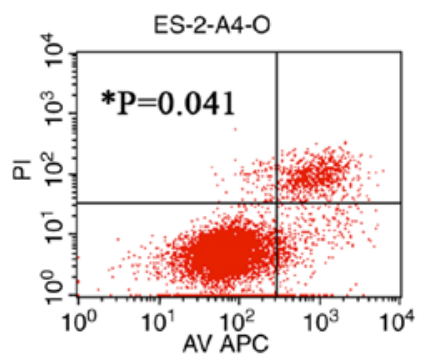

Quad Events \% Gated \% Total X Mean Y Mean

\begin{tabular}{rrrrrr} 
UL & 94 & 1.11 & 0.94 & 192.41 & 95.53 \\
\hline
\end{tabular}

\begin{tabular}{rrrrrr} 
LL & 7184 & 84.81 & 71.84 & 81.72 & 4.94 \\
\hline LR & 393 & 4.64 & 3.93 & 848.61 & 8.92
\end{tabular}

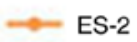

ES-2-A4-O

ES-2-A4-O+

BAY 11-2078

ES-2+

BAY 11-2078
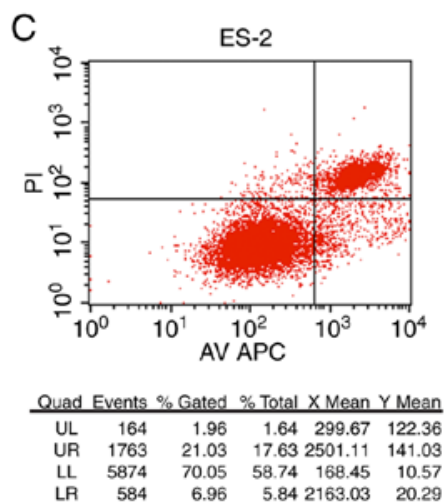

Figure 7. Effects of ANXA4 and NF- $\mathrm{BB}$ p50 on cell proliferation and apoptosis. (A) Expression changes of Cyclin D1 and Bcl-2 in ES-2 cells before and after transfection of the ANXA4 gene, and addition of the NF- $\kappa$ B inhibitor. (B) Proliferation capacity of ES-2 cells before and after addition of the NF- $\kappa$ B inhibitor, detected via the MTT assay. (C) Apoptosis of ES-2 cells before and after addition of the NF- $\mathrm{B}$ inhibitor, detected via Annexin V-APC/PI double-staining.

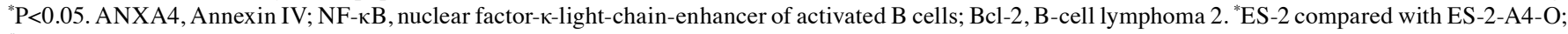
${ }^{\#}$ ES-2-A4-O compared with ES-2-A4-O + BAY 11-2078.

First, the present study established the ANXA4 gene-expressing and ANXA4 gene-silencing cell lines; secondly, NF- $\mathrm{kB}$ p50 expression was detected both before and after transfection, followed by western blotting and immunocytochemistry analyses. The results demonstrated that NF- $\mathrm{KB}$ p50 expression changed over ANXA4, and suggested that upregulating ANXA4 may enhance its binding with $\mathrm{NF}-\kappa \mathrm{B}$ p50. The ANXA4 gene-transfected OCCC cell lines were additionally treated with the NF- $\mathrm{BB}$ inhibitor, and the changes in the capacity of cell proliferation and apoptosis were subsequently assessed. The results demonstrated that the proliferation capacity of ANXA4 gene-transfected cells increased and cell apoptosis decreased, while the proliferation capacity of ANXA4 gene-transfected cells treated with the NF- $\mathrm{KB}$ inhibitor decreased and cell apoptosis increased. Collectively, these results suggest that ANXA4 bound to

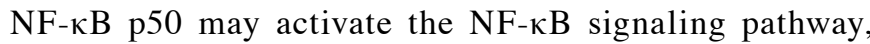
promote proliferation and inhibit apoptosis of OCCC cells. The expression levels of the target molecules associated with cell proliferation and apoptosis, Cyclin D1 and Bcl-2, downstream of the NF- $\mathrm{KB}$ signaling pathway (34) were detected both before and after transfection of the ANXA4 gene and addition of the NF- $\kappa B$ inhibitor, respectively. The results demonstrated that the expression levels of Cyclin D1 and Bcl-2 increased following transfection of the ANXA4 gene, and significantly decreased following addition of the NF- $\kappa B$ inhibitor. This confirmed that ANXA4 bound to NF- $\kappa \mathrm{B}$ p50 promoted the expression of NF- $\kappa \mathrm{B}$ downstream target molecules, Cyclin D1 and $\mathrm{Bcl}-2$, and thus facilitated cell proliferation and inhibited cell apoptosis.

Previous studies have reported that ANXA4 is particularly expressed in pathological tumor subtypes, for example, its 
expression is significantly higher in thyroid follicular carcinoma and medullary carcinoma compared with other subtypes of thyroid cancer, and also higher in salivary pleomorphic tumor and Warthin tumor compared with other subtypes of salivary tumor $(35,36)$. Thus, ANXA4 is considered a marker to distinguish different subtypes of thyroid cancer and salivary tumor. Similarly, in OC, ANXA4 is highly expressed in the pathological subtypes compared with ovarian serous carcinoma, and is significantly upregulated in OCCC (37). The results of the present study demonstrated that ANXA4 can bind to NF- $\mathrm{NB}$ p50 in OCCC cells, thus promoting cell proliferation and inhibiting cell apoptosis.

A previous study has confirmed that the particularly high ANXA4 expression in OCCC is regulated by wild-type p53 (38). p53 is classified into wild-type and mutant type. Reports have suggested that p53 is mostly wild-type rather than mutant type in OCCC, which was confirmed by the results of the present study, demonstrating that mutant p53 was expressed at lows levels in OCCC. Wild-type p53 can bind with the upstream transcription initiation site of the ANXA4 gene and positively regulate ANXA4 expression in cells. Following transfection of wild-type p53 siRNA, both wild-type p53 and ANXA4 expression simultaneously decrease; however, this effect is absent in mutant type p53 $(39,40)$. The results of the present study also confirmed that ANXA4 is weakly expressed in OCCC tissues that express mutant p53, while highly expressed in OCCC tissues without mutant p53 expression. The expression of ANXA4 and mutant p53 exhibited a negatively linear correlation. It is well-known that wild-type p53, a key factor in regulating cell-cycle arrest, cell aging and apoptosis, is the most effective tumor-inhibiting gene. Exogenously acquired wild-type p53 can inhibit autophagy, reverse drug resistance and promote apoptosis of tumor cells $(41,42)$. However, the molecular mechanism underlying the role of ANXA4 on tumor progression remains unclear. A previous report has demonstrated that $\mathrm{NF}-\kappa \mathrm{B}$ inhibits the transcription of p53-dependent genes, while the NF- $\kappa \mathrm{B}$ inhibitor suppresses the cytoplasmic-to-nuclear shift of $\mathrm{NF}-\kappa \mathrm{B}$, thus inhibiting the transcriptional activity of $\mathrm{NF}-\kappa \mathrm{B}$ and increasing the expression of p53 downstream target molecules, including p21, in cells (43). The results of the present study demonstrated that ANXA4 and $\mathrm{NF}-\kappa \mathrm{B}$ p50 are overexpressed and interact with one another in OCCC tissues and cells. Bioinformatics analysis indicated that

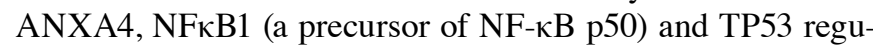
late each other and form complex regulatory associations with other genes, further activating the NF- $\mathrm{B}$ signaling pathway, apoptosis, cell cycle, and the PI3K/Akt and MAPK signaling pathways, thus participating in cell proliferation, apoptosis and other biological processes such as cell adhesion; for all that, the mechanism of ANXA4 complex action is still warranted more in-depth and concentrated investigations.

In conclusion, the results of the present study demonstrated that wild-type p53 activates ANXA4 transcription and promotes its expression, which subsequently binds to $\mathrm{NF}-\kappa \mathrm{B}$ p50 and enters the nuclei of cells, activating the $\mathrm{NF}-\kappa \mathrm{B}$ signaling pathway. The complex biological regulation among wild-type p53, ANXA4 and NF- $\kappa$ B p50 increases the expression of Cyclin D1 and Bcl-2, thus facilitating cell proliferation and inhibiting cell apoptosis, while promoting the malignant progression of tumors. Taken together, the results of the present study suggest that $\mathrm{ANXA} 4 / \mathrm{NF}-\kappa \mathrm{B}$ p50 complexes play a critical role in tumorigenesis of $\mathrm{OCCC}$, and thus may provide novel ideas for early detection and surveillance for OCCC treatment.

\section{Acknowledgements}

Not applicable.

\section{Funding}

The present study was funded by The National Natural Science Foundation of China (grant nos. 81172491, 81101527, 8147243 and 81672590) and the Outstanding Scientific Fund of Shengjing Hospital (grant no. 201804).

\section{Availability of data and materials}

All data generated or analyzed during this study are included in this published article.

\section{Authors' contributions}

BL designed the present study. JL and HW performed most of the experiments, and MZ and LD participated in the experiments. MZ and XZ performed the statistical analyses. All authors read and approved the final manuscript.

\section{Ethics approval and consent to participate}

Samples were fully encoded to protect patient confidentially. All procedures performed involving human participants were in accordance with the ethical standards of the Ethical Committee of Shengjing Hospital of China Medical University (Shenyang, China, approval no. 2013PS66K). The ethics committee waived the need for patient consent, as the patient information was withheld in this retrospective study.

\section{Patient consent for publication}

Not applicable.

\section{Competing interests}

The authors declare that they have no competing interests.

\section{References}

1. Siegel RL, Miller KD and Jemal A: Cancer statistics, 2018. CA Cancer J Clin 68: 7-30, 2018.

2. Bamias A, Psaltopoulou T, Sotiropoulou M, Haidopoulos D, Lianos E, Bournakis E, Papadimitriou C, Rodolakis A, Vlahos G and Dimopoulos MA: Mucinous but not clear cell histology is associated with inferior survival in patients with advanced stage ovarian carcinoma treated with platinum-paclitaxel chemotherapy. Cancer 116: 1462-1468, 2010.

3. Matsuzaki S, Yoshino K, Ueda Y, Matsuzaki S, Kakuda M, Okazawa A, Egawa-Takata T, Kobayashi E and Kimura T: Potential targets for ovarian clear cell carcinoma: A review of updates and future perspectives. Cancer Cell Int 15: 117, 2015.

4. Crotzer DR, Sun CC, Coleman RL, Wolf JK, Levenback CF and Gershenson DM: Lack of effective systemic therapy for recurrent clear cell carcinoma of the ovary. Gynecol Oncol 105: 404-408, 2007. 
5. Sugiyama T, Kamura T, Kigawa J, Terakawa N, Kikuchi Y, Kita T, Suzuki M, Sato I and Taguchi K: Clinical characteristics of clear cell carcinoma of the ovary: A distinct histologic type with poor prognosis and resistance to platinum-based chemotherapy. Cancer 88: 2584-2589, 2000.

6. Itamochi H, Kigawa J and Terakawa N: Mechanisms of chemoresistance and poor prognosis in ovarian clear cell carcinoma. Cancer Sci 99: 653-658, 2008.

7. Smith RA, Manassaram-Baptiste D, Brooks D, Doroshenk M, Fedewa S, Saslow D, Brawley OW and Wender R: Cancer screening in the United States, 2015: A review of current American cancer society guidelines and current issues in cancer screening. CA Cancer J Clin 65: 30-54, 2015.

8. Lin LL, Huang HC and Juan HF: Revealing the molecular mechanism of gastric cáncer marker annexin A4 incancer cell proliferation using exon arrays. PLoS One 7: e44615, 2012.

9. Huang HL, Yao HS, Wang Y, Wang WJ, Hu ZQ and Jin KZ: Proteomic identification of tumor biomarkers associated with primary gallbladder cancer. World J Gastroenterol 20: 5511-5518, 2014.

10. Liu YY, Ge C, Tian H, Jiang JY, Zhao FY, Li H, Chen TY, Yao M and Li JJ: The transcription factor Ikaros inhibits cell proliferation by downregulating ANXA4 expression in hepatocellular carcinoma. Am J Cancer Res 7: 1285-1297, 2017.

11. Wang H, Deng L, Cai M, Zhuang H, Zhu L, Hao Y, Gao J, Liu J, Li X and Lin B: Annexin A4 fucosylation enhances its interaction with NF- $\mathrm{kB}$ p50 and promotes tumor progression of ovarian clear cell carcinoma. Oncotarget 8: 108093-108107, 2016.

12. Jeon YJ, Kim DH, Jung H, Chung SJ, Chi SW, Cho S, Lee SC, Park BC, Park SG and Bae KH: Annexin A4 interacts with the NF-kappaB p50 subunit and modulates NF-kappaB transcriptional activity in a $\mathrm{Ca}^{2+}$-dependent manner. Cell Mol Life Sci 67: 2271-2281,2010.

13. Bolshakova A, Magnusson KE, Pinaev $\mathrm{G}$ and Petukhova $\mathrm{O}$ : Functional compartmentalisation of NF- $\mathrm{KB}$-associated proteins in A431 cells. Cell Biol Int 37: 387-396, 2013.

14. Fang Y, Chai Z, Wang D, Kuang T, Wu W and Lou W: DNA-PKcs deficiency sensitizes the human hepatoma HepG2 cells to cisplatin and 5-fluorouracil through suppression of the PI3K/Akt/NF- $\kappa \mathrm{B}$ pathway. Mol Cell Biochem 399: 269-278, 2015.

15. Basso F, Rocchetti F, Rodriguez S, Nesterova M, Cormier F, Stratakis CA, Ragazzon B, Bertherat J and Rizk-Rabin M: Comparison of the effects of PRKAR1A and PRKAR2B depletion on signaling pathways, cell growth, and cell cycle control of adrenocortical cells. Horm Metab Res 46: 883-888, 2014

16. Naugler WE and Karin M: NF-kappa B and cancer-identifying targets and mechanisms. Curr Opin Genet Dev 18: 19-26, 2008.

17. Luo JL, Kamata $\mathrm{H}$ and Karin M: IKK/NF-kappa B signaling: Balancing life and death-a new approach to cancer therapy. J Clin Invest 115: 2625-2632, 2005.

18. Masuishi Y, Arakawa N, Kawasaki H, Miyagi E, Hirahara F and Hirano H: Wild-Type p53 enhances annexin IV gene expression in ovarian clear cell adenocarcinoma. FEBS J 278: 1470-1483, 2011.

19. Bykov VJ, Eriksson SE, Bianchi J and Wiman KG: Targeting mutant p53 for efficient cancer therapy. Nat Rev Cancer 18 89-102, 2018

20. Pereira A, Pérez-Medina T, Magrina JF, Magtibay PM, Rodríguez-Tapia A, Peregrin I, Mendizabal E and Ortiz-Quintana L: International federation of gynecology and obstetrics staging classification for cancer of the ovary, fallopian tube, and peritoneum: Estimation of survival in patients with node-positive epithelial ovarian cancer. Int J Gynecol Cancer 25 : 49-54, 2015.

21. Daly MB, Pilarski R, Berry M, Buys SS, Farmer M, Friedman S, Garber JE, Kauff ND, Khan S, Klein C, et al: NCCN guidelines insights: Genetic/Familial high-risk assessment: Breast and ovarian, version 2.2017. J Natl Compr Canc Netw 15: 9-20, 2017.

22. Wang H, Tan M, Zhang S, Li X, Gao J, Zhang D, Hao Y, Gao S, Liu J and Lin B: Expression and significance of CD44, CD47 and c-met in ovarian clear cell carcinoma. Int J Mol Sci 16 : 3391-3404, 2015

23. Iwamori M, Tanaka K, Kubushiro K, Lin B, Kiguchi K, Ishiwata I, Tsukazaki K and Nozawa S: Alterations in the glyolipid composition and cellular properties of ovarian carcinoma-derived RMG-1 cells on transfection of the $\alpha 1,2$-fucosyltransferase gene. Cancer Sci 96: 26-30, 2005.
24. Shannon P, Markiel A, Ozier O, Baliga NS, Wang JT, Ramage D, Amin N, Schwikowski B and Ideker T: Cytoscape: A software environment for integrated models of biomolecular interaction networks. Genom Res 13: 2498-2504, 2003.

25. Wade J, Armon S and McNally OM: Ovarian clear cell carcinoma recurrence presenting as subcutaneous nodules. Eur J Gynaecol Oncol 37: 575-577, 2016.

26. Elvin JA, Chura J, Gay LM and Markman M: Comprehensive genomic profiling (CGP) of ovarian clear cell carcinomas (OCCC) identifies clinically relevant genomic alterations (CRGA) and targeted therapy options. Gynecol Oncol Rep 20: 62-66, 2017.

27. Dolcet X, Llobet D, Pallares J and Matias-Guiu X: NF- $\kappa$ B in development and progression of human cancer. Virchows Arch 446: 475-482, 2005

28. DiDonato JA, Mercurio F and Karin M: NF- $\kappa \mathrm{B}$ and the link between inflammation and cancer. Immunol Rev 246: 379-400, 2012.

29. Chariot A: The NF-kappaB-independent functions of IKK subunits in immunity and cancer. Trends Cell Biol 19: 404-413, 2009.

30. Rao P, Hayden MS, Long M, Scott ML, West AP, Zhang D, Oeckinghaus A, Lynch C, Hoffmann A, Baltimore D and Ghosh S: IkappaBbeta acts to inhibit and activate gene expression during the inflammatory response. Nature 466: 1115-1119, 2010.

31. Wan F and Lenardo MJ: The nuclear signaling of NF-kappaB: Current knowledge, new insights, and future perspectives. Cell Res 20: 24-33, 2010.

32. Patel M, Horgan PG, McMillan DC and Edwards J: NF- $\mathrm{BB}$ pathways in the development and progression of colorectal cancer. Transl Res 197: 43-56, 2018.

33. Perkins ND: The diverse and complex roles of NF- $\kappa B$ subunits in cancer. Nat Rev Cancer 12: 121-132, 2012.

34. Tilborghs S, Corthouts J, Verhoeven Y, Arias D, Rolfo C, Trinh XB and van Dam PA: The role of nuclear factor-kappa B signaling in human cervical cancer. Crit Rev Oncol Hematol 120: 141-150, 2017.

35. Wei B, Guo C, Liu S and Sun MZ: Annexin A4 and cancer. Clin Chim Acta 447: 72-78, 2015.

36. Yao $\mathrm{H}$, Sun $\mathrm{C}, \mathrm{Hu} \mathrm{Z}$ and Wang $\mathrm{W}$ : The role of annexin $\mathrm{A} 4$ in cancer. Front Biosci (Landmark Ed) 21: 949-957, 2016.

37. Kim A, Serada S, Enomoto T and Naka T: Targeting annexin A4 to counteract chemoresistance in clear cell carcinoma of the ovary. Expert Opin Ther Targets 14: 963-971, 2010.

38. Hatoum D, Yagoub D, Ahadi A, Nassif NT and McGowan EM: Annexin/S100A protein family regulation through p14ARF-p53 activation: A role in cell survival and predicting treatment outcomes in breast cancer. PLoS One 12: e0169925, 2017.

39. Perego P, Giarola M, Righetti SC, Supino R, Caserini C, Delia D, Pierotti MA, Miyashita T, Reed JC and Zunino F: Association between cisplatin resistance and mutation of p53 gene and reduced bax expression in ovarian carcinoma cell systems. Cancer Res 56: 556-562, 1996.

40. Matsuo Y, Tashiro H, Yanai $H$, Moriya $T$ and Katabuchi $H$ : Clinicopathological heterogeneity in ovarian clear cell adenocarcinoma: A study on individual therapy practice. Med Mol Morphol 48: 146-154, 2015.

41. Shi J, Xiao H, Li J, Zhang J, Li Y, Zhang J, Wang X, Bai X, Tao K, Hu D and Guan H: Wild-Type p53-modulated autophagy and autophagic fibroblast apoptosis inhibit hypertrophic scar formation. Lab Invest 98: 1423-1437, 2018.

42. Galmarini CM, Kamath K, Vanier-Viornery A, Hervieu V, Peiller E, Falette N, Puisieux A, Jordan AM and Dumontet C: Drug resistance associated with loss of p53 involves extensive alterations in microtubule composition and dynamics. $\mathrm{Br}$ J Cancer 88: 1793-1799, 2003.

43. Meylan E, Dooley AL, Feldser DM, Shen L, Turk E, Ouyang C and Jacks T: Requirement for NF- $\kappa$ B signaling in a mouse model of lung adenocarcinoma. Nature 462: 104-107, 2009.

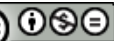

This work is licensed under a Creative Commons Attribution-NonCommercial-NoDerivatives 4.0 International (CC BY-NC-ND 4.0) License. 